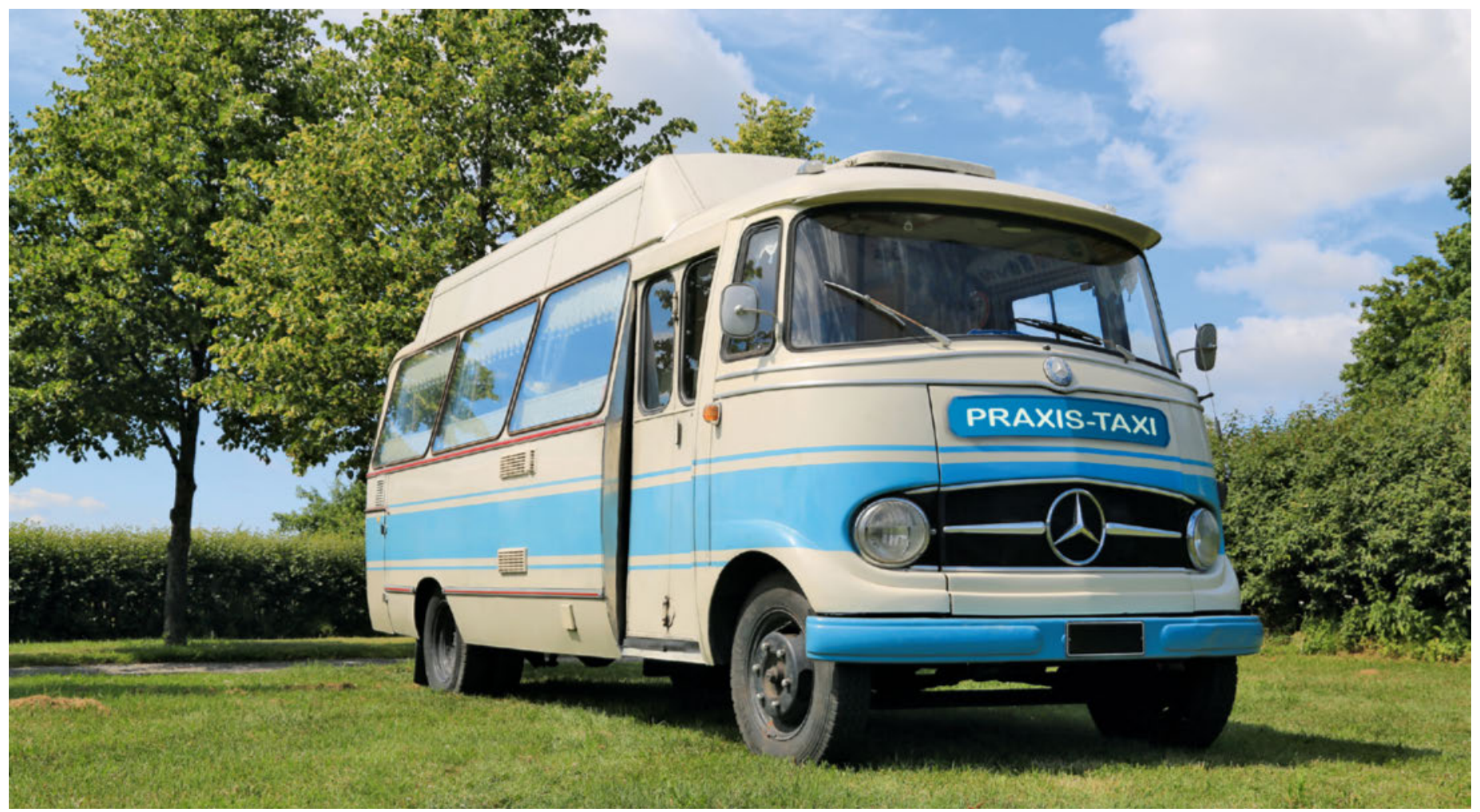

Laut Dr. G. Logen zahlen sich die Anschaffungskosten von 250000 CHF für das selbstfahrende «Patienten-Taxi» mehr als aus - sein Wartezimmer ist seither immer gut gefüllt.

\title{
Der autonom fahrende Kleinbus
}

\section{EMH News Service}

Vergangene Woche berichteten wir in der SÄZ über die ApoDoc Hardbrücke in Zürich-West - die Hausarztpraxis mit Walk-In-Service, Apotheke und Café in einem [1]. Heute stellen wir Ihnen vor, wie Patienten in Ihre Praxis kommen, für die «Walk-In» keine Option ist. Wir blicken zurück: Noch vor einem Jahr läuft die Praxis von Dr. med. G. Logen in der Innerschweiz gar nicht gut. Viele seiner älteren Patienten, die nicht mehr gut zu Fuss sind, scheuen den Weg in die Praxis, da die nächstgelegene Bushaltestelle über 2 Kilometer entfernt liegt. Das Wartezimmer ist meistens leer, nicht selten ist für ihn und seine Praxisassistentin schon vor 16.00 Uhr Feierabend. Doch dann hat Dr. G. Logen eine zündende Idee.

Statt in eine neue Praxisausstattung oder neue Geräte zu investieren, schafft er sich im Sommer für 250000 Franken einen autonom fahrenden Kleinbus an. Dieser sammelt nun 4-mal pro Tag seine chronisch kranken und immobilen Patienten ein und fährt sie - dank GPS und Radar - gruppenweise zur Praxis. Rollatoren und Rollstühle werden ebenfalls autonom verladen. Unter- wegs gibt es Gesundheitstipps über Lautsprecher, an Donnerstagen Live-Musik, auf dem Rückweg hält der Bus vor der Apotheke und beim Metzger. Wundversorgungen, Laborkontrollen und eine regelmässige Fussgymnastik sind kein Problem mehr. Nicht wenige seiner Patienten, gibt Dr. G. Logen allerdings zu, fahren gerne mit dem Bus und haben eigentlich keinen triftigen Grund, um die Praxis aufzusuchen.

Dr. G. Logen kann sich seit einem halben Jahr über mangelnde Arbeit nicht mehr beklagen. Am Wochenende nutzt er den Bus für den Notdienst, und da er nicht selber fahren muss, ist auch wieder ein Gläschen Wein am Abend möglich. Inzwischen hat er genug verdient, um sich einen zweiten Bus leisten zu können. Dieser soll zum Leidwesen seiner Kollegen auch Patienten aus den Nachbargemeinden auflesen.

\section{Bildnachweis}

(c) Taina Sohlman | Dreamstime.com, bearbeitet von EMH/Schwabe

\section{Literatur}

1 EMH News Service. «Innovative Geschäftsmodelle für Ihre Praxis» Teil I: Die ApoDoc Hardbrücke. Schweiz Ärztezeitung. 2018; 99(12):365. 